\title{
Differential Analyses of Peripheral Blood Parameters in CCR5 Inhibition-treated Colorectal Cancer Patients Reveal Dynamic Changes Linked to Clinical Outcomes
}

\author{
AZAZ AHMED ${ }^{1,2}$ and NIELS HALAMA ${ }^{1,2,3}$ \\ ${ }^{I}$ German Cancer Research Center (DKFZ), Department of Translational Immunotherapy, Heidelberg, Germany; \\ ${ }^{2}$ National Center for Tumor Diseases, Heidelberg, Germany; \\ ${ }^{3}$ Helmholtz Institute for Translational Oncology (HI-TRON), Mainz, Germany
}

\begin{abstract}
Background/Aim: Chemokine receptor inhibition is an immunotherapy that modulates the innate arm of the immune system. Previous work in microsatellite-stable metastatic colorectal cancer showed an exploitive loop that could be successfully targeted via $C$-C-motive-chemokine-receptor 5 (CCR5) specific blocking, resulting in a selective anti-tumoral activation of macrophages. In the respective trial (MARACON trial, NCT01736813) the peripheral blood laboratory markers and cytokine values were measured over time. Little is known on their role as biomarkers or stratification parameters in immunotherapy trials. Patients and Methods: Systematic analyses of key laboratory parameters are presented, highlighting specific dynamics of lymphocyte and monocyte percentages, lactate dehydrogenase as well as interleukin-6 and interleukin-8 levels as parameters of a systemic inflammatory readout. Results: Specific dynamical changes of lymphocyte and monocyte compositions were noted between different patients, showing a stabilization (or increase) versus decreased numbers over time for monocytes. While lactate dehydrogenase, interleukin-6 and interleukin-8 showed almost uniformly rising levels over time, the systemic monocyte patterns prompted a further evaluation. Stabilized or increasing monocyte percentages were associated with improved overall survival (Kaplan Meier analysis, $p=0.025$ ) and with induced overt radiologic necrosis in patients. Conclusion: The observed
\end{abstract}

This article is freely accessible online.

Correspondence to: Niels Halama, German Cancer Research Center (DKFZ), Im Neuenheimer Feld 260, 69120 Heidelberg, Germany. Tel: +49 6221567229, Fax: +49 6221567225, e-mail: niels.halama@ nct-heidelberg.de

Key Words: Colorectal cancer, immunotherapy, microsatellite stability, CCR5 inhibition, chemokine, innate immunity, macrophages, monocytes. association between monocyte dynamics and imaging findings as well as overall survival suggests that analyses of dynamical parameters in the peripheral blood should be implemented in immunotherapy trials.

In microsatellite-stable metastatic colorectal cancer, classical checkpoint-inhibition immunotherapy has not shown promising results thus far (1-5). This is in stark contrast to the presence of varying compositions of immune cells within the tumor microenvironment, with a clear prognostic role of cells from the adaptive arm of the immune system (6-11). Given the dire clinical situation in advanced metastatic colorectal cancer with overall survival rates of just around 30 months $(12,13)$, the possibility of modulating other components of the immune system is promising and needed. In light of this situation, new avenues were investigated trying to harness the innate arm of the immune system (utilizing $e . g$. abundant myeloid cells) to break the immunological unresponsiveness of microsatellite-stable colorectal cancer (14). Systematic analyses with fully human explant model systems revealed a significant role of the CCR5 axis in metastatic colorectal cancer. In detail, a clinically relevant repolarization potential of CCR5 inhibition (CCR5i) in macrophages was observed (15-17). The anti-tumor activation of macrophages resembles an activation of an anti-viral program in myeloid cells, thereby pointing to the crossroad of anti-tumor immunity and infection (18). Maraviroc is a small molecule inhibitor with high selectivity for CCR5 and was originally developed for the treatment of human immunodeficiency virus (19). Oral intake of Maraviroc was continuous throughout the trial and very well tolerated with no significant side effects (17). During the clinical study, one aspect was visible from early on: selective CCR5i leads to radiological changes in patients. Systematic imaging studies showed overt necrosis arising in some of the patients, formally not shrinking the lesions but leading to central necrosis with outward spreading. Histological analyses of serial biopsies revealed that all patients showed tumor cell 
Table I. Patient characteristics.

\begin{tabular}{|c|c|c|c|c|c|c|c|c|c|}
\hline \multirow[t]{2}{*}{ Pat } & \multirow[t]{2}{*}{$\mathrm{T}$} & \multirow[t]{2}{*}{$\mathrm{N}$} & \multirow[t]{2}{*}{ M } & \multirow{2}{*}{$\begin{array}{c}\text { Synchronous/ } \\
\text { Metachronous M }\end{array}$} & \multirow[t]{2}{*}{$\mathrm{G}$} & \multirow[t]{2}{*}{ Age } & \multirow[t]{2}{*}{ Gender } & k-RAS & BRAF \\
\hline & & & & & & & & \multicolumn{2}{|c|}{ Wild-type (wt) or mutated (mut } \\
\hline 1 & 3 & 2 & 1 & Syn & 2 & 57 & Male & Mut* & WT \\
\hline 2 & 4 & 2 & 0 & Met & 2 & 67 & Female & WT & WT \\
\hline 3 & 3 & 2 & 1 & Syn & 3 & 32 & Female & WT & WT \\
\hline 4 & 3 & 2 & 0 & Met & 2 & 31 & Male & WT & Mut \\
\hline 5 & 4 & 1 & 1 & Syn & NA & 66 & Male & Mut* & WT \\
\hline 6 & 3 & 2 & 1 & Syn & 2 & 64 & Male & Mut* & WT \\
\hline 7 & 4 & 0 & 0 & Met & 3 & 61 & Male & WT & WT \\
\hline 8 & 3 & 1 & 1 & Syn & 2 & 61 & Male & Mut & WT \\
\hline 9 & 3 & 1 & 1 & Syn & 1 & 69 & Male & WT & WT \\
\hline 10 & 3 & 0 & 1 & Syn & 2 & 53 & Female & WT & WT \\
\hline 11 & 3 & 1 & 1 & Syn & 3 & 66 & Male & Mut & WT \\
\hline 12 & 4 & 2 & 0 & Met & 2 & 58 & Female & WT & WT \\
\hline
\end{tabular}

All patients had liver metastases (M1) at the time of trial participation. Herein TNM (T=tumor stage, N=lymph node status, M=Metastatic status, $\mathrm{G}=$ grading) of initial diagnosis is also given, all patients had received all standard-of-care treatments at the time of trial participation. "Mut" indicates mutation, "WT" indicates wildtype without mutation. *Patients with "codon 12 mutation".

necrosis on the tissue level upon CCR5i treatment. The pronounced tissue level response was associated with radiologic findings of newly identifiable necrosis formation. Beyond the liver, effects were also observed in other organs, e.g. lung lesions. With CCR5i having effects well beyond the liver metastases, the question appeared whether systemic parameters are linked to the observed tissue effects. Systematic peripheral blood analyses were performed during the trial, including differential blood displays and lactate dehydrogenase measurements as a reflection of tumor cell activity. Also, interleukin-6 (IL-6) and interleukin-8 (IL-8) levels were measured as key inflammatory parameters. The progressive disease in patients after weeks or months of monotherapy treatment, was paralleled by the discovery of the uniform tumor cell death-inducing properties of CCR5i. Consequently, this leads to the question whether surrogate systemic biomarkers or peripheral blood parameters are detectable, displaying the microenvironmental CCR5i effects. Herein, the measurements of these key parameters in context of the clinical course of individual patients are presented.

\section{Patients and Methods}

Study design and concept. The details have been reported in previous studies of our group $(17,20)$. In short, $n=12$ ( $n=14$ with the final extended cohort) patients with histologically proven metastatic colorectal cancer with liver metastases were included in the trial, after all available standard-of-care therapies had been used previously. The patients were treated with maraviroc $300 \mathrm{mg}$, with concomitant serial biopsies before and under treatment. Peripheral blood samples were obtained per protocol and treatment follow-up was also obtained. For this analysis the coupled datasets from the initial cohort $(n=12)$ were used.
Clinical data. The study approval by the local Ethics Committee was obtained (357/2012). Follow-up for each patient included the complete time period until remission or disease progression occurred and also encompassed overall survival. Patients were included with stage UICC IV CRC after metastatic disease was histologically proven (see Table I for patient characteristics). All tumor samples were analyzed for microsatellite-instability using the polymorphic markers BAT25, BAT26, and CAT25 as described earlier (20) and all metastases showed microsatellite-stability.

Cytokine measurements. A two-laser array reader system (Bio-Rad, Munich, Germany) simultaneously quantifies all cytokines and chemokines of interest (11). Bio-Plex Manager 4.1.1 was used to analyze and generate standard curves and concentrations, calculated on the basis of the 5-parameter logistic plot regression formula. Briefly, serum samples were used according to the manufacturer's instruction with respective dilutions. Calibration of the investigated analytes was performed as per the manufacturer's instructions (BioRad, see also for accuracy and precision http://www.biorad.com/webroot/web/pdf/lsr/literature/Bulletin_5803A.pdf).

Differential blood display panel. Samples were analyzed in the Core Laboratory Facilities of the University Hospital Heidelberg for complete blood counts and lactate dehydrogenase (normal range $<308 \mathrm{U} / \mathrm{l}$ ), according to accredited standards (DIN EN ISO 15189, D-ML-13060-01-00).

Statistical analyses. Survival curves were computed using the Kaplan-Meier estimator. All statistical analyses were conducted with $\mathrm{R}$ version 4.0.2.

\section{Results}

Lactate dehydrogenase and IL-6 and IL-8. Lactate dehydrogenase (LDH) is well known to reflect tumor growth and poor prognosis (21), which was confirmed in this small cohort 
with a trend for poorer overall survival $(p=0.051)$. Comparing the LDH distribution with the interleukin 6 and 8 levels (Figure $1)$, a general increase in interleukin-6 was observable in the analyzed patients. Interleukin- 8 showed a somewhat more diverse pattern in the limited number of patients, with increasing levels over time (three out of four patients).

Lymphocyte and monocyte percentage dynamics. Effector T cell to myeloid cell ratios and percentages have shown prognostic relevance in many tumor entities (22-24). Lymphocyte and monocyte percentages were therefore analyzed in more detail, especially as the CCR5i treatment was hypothesized to alter also tissue infiltration (and peripheral blood composition?) for either lymphocytes or monocytes or both (25-28). Lymphocyte percentages showed complex changes over time that could not be classified into meaningful categories. Increasing percentages of lymphocytes over time (comparing first to last measurement) were not associated with either better overall survival $(p=0.52)$ nor were decreasing percentages associated $(p=0.48)$. For monocyte percentages, two categories of patients could be identified: monocyte percentage stabilization/increase over time versus monocyte percentage decrease over time.

Association between monocyte percentage change and clinical parameters. The two groups of monocyte percentage changes over time showed an association with overall survival $(p=0.025)$ (Figure 2). In order to see whether there are other aspects of association with the clinical course, the groups were investigated in relation to radiologial findings. One observed specific radiological effect of CCR5i is the induction of central necrosis in metastases. Clustering the patients' radiology findings according to the grouping of monocyte percentage change over time revealed a dichotomy. The necrosis cases are appearing only in the patients with stable or increased monocyte percentages (Figure 3).

\section{Discussion}

The investigation of the effects of a specific immunotherapy in metastatic disease has a multitude of challenges. Modification of the innate arm of the immune system is especially challenging as multiple factors from dietary influences to concomitant medication influence activity of innate immune cells simultaneously (14). Further complexity arises from different immunological microenvironments at different metastatic sites (14). Optimally, any immunological intervention has to modulate all involved sites and successfully activate the immune system against the tumor. This desired inflammatory immune response is distinct to a chronic inflammatory state that promotes tumor growth (29). But what changes are induced by a specific immunological intervention in the organ tumor microenvironment in contrast to the peripheral blood? Generation of immune cells and trafficking of immune cells into the tumor are vital parts of an effective immunotherapy. CCR5 is a universal molecule for lymphoid and myeloid cell orchestration (30-34), exhibiting complex functions in infections, inflammation and antigenpresentation. Also, blocking CCR5 in metastatic colorectal cancer leads to repolarization of macrophages. Whereas dynamic changes in the microenvironment of metastases can be analyzed with serial biopsies, changes in the periphery have to be investigated separately. In our presented work, measuring key molecules of inflammation and key cells in the periphery under treatment revealed distinct dynamics, which were interconnected with the outcome of patients. While LDH has appeared in various investigations as a marker of tumor growth, the IL-8 levels are known to be a marker for tumor progression in colorectal cancer. LDH here appears as a reflection of tumor growth despite initial histological tumor cell necrosis in all patients. The dynamics of LDH in relation to the clinical course appear concordant, whereas IL-8 levels are not conclusive in the limited set of patient samples. IL-6 as a marker of (systemic) inflammation on the other hand showed increasing levels in all available patient samples, underscoring a shift in the inflammatory state. Whether this is for the benefit or not cannot be solved with this dataset now, but it shows that there is a regulatory difference between the two interleukins and increasing levels of one cannot predict the alteration of the other. Looking into cellular components, the percentage change in lymphocytes is mainly represented by a decline (2 out of 12 ) and analysis in the MARACON trial participants did not indicate an association with the clinical course. In contrast, monocyte percentage changes showed two clear groups. With the known regulatory properties of CCR5 on myeloid cells, this observation raises many questions. The reduction of monocyte numbers suggests an influx of these cells into tissues or a loss of generation of these cells. In those patients with stable or increasing numbers, there is either a reduced influx into the tissue or an enhanced production of these cells. Previous analyses (17) showed that differentiated CD11b+ macrophages obtain anti-tumoral properties upon CCR5i. The induced repolarization of macrophages also reduces levels of tumor promoting CD163+ cells (17). Observing the increased necrosis of tumor cells leading to radiologically measurable differences in those patients with stable or increasing monocyte percentages could suggest an increased influx of monocytes, which then differentiate and act on tumor cells, thereby leading to an increased anti-tumoral effect. In patients with decreasing monocytes, one possible problem could be in the capacity to produce monocytes in the bone marrow. Preceding chemotherapies or infiltration of tumor could impede the production of cells in the bone marrow. Clearly, further studies are needed to elucidate this aspect. Our findings however indicate, that a) CCR5i effects might rely on the 

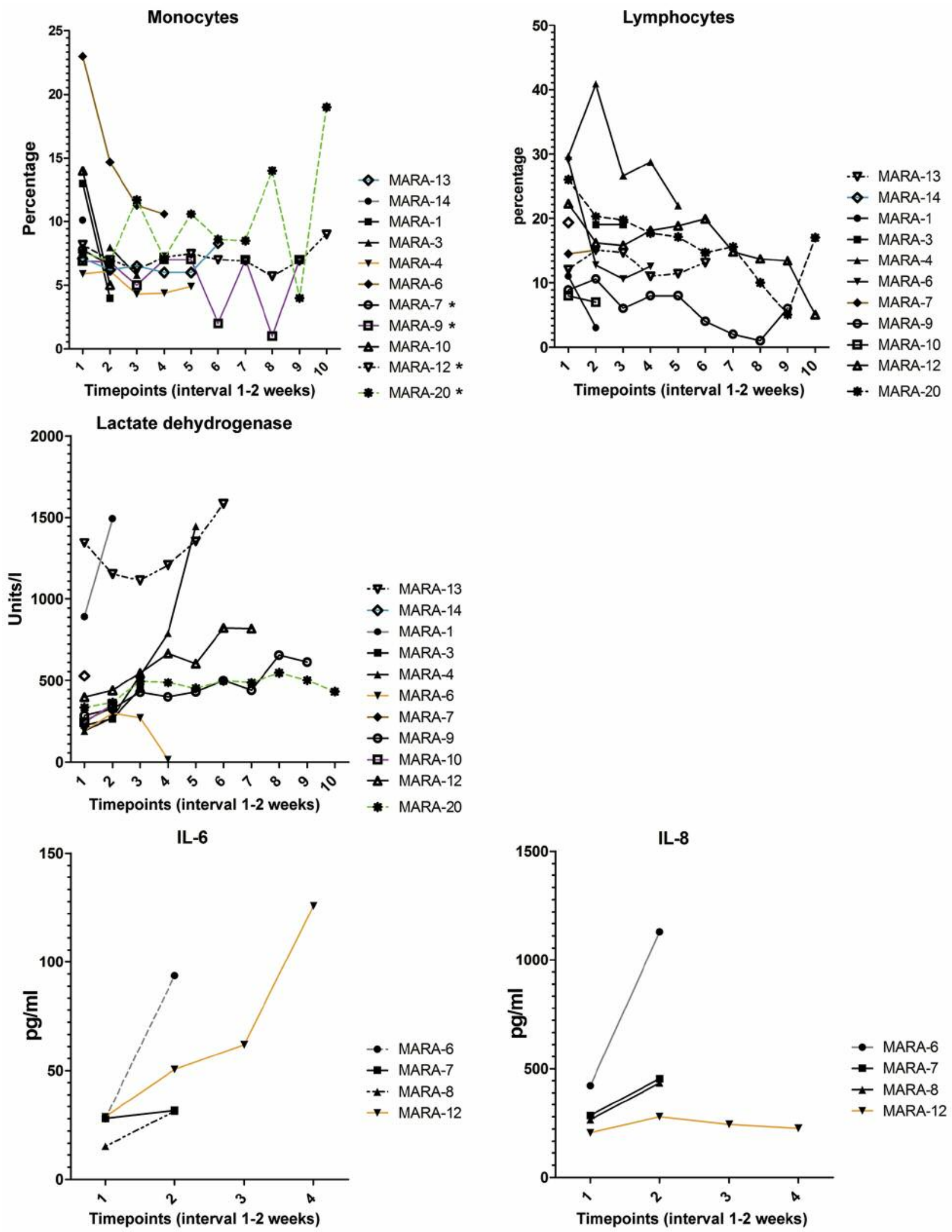

Figure 1. Changes of different peripheral blood parameters in colorectal cancer patients under CCR5i therapy. Asterisks indicate patients with stable or increased monocytes percentages over time (first to last measurement comparison). 


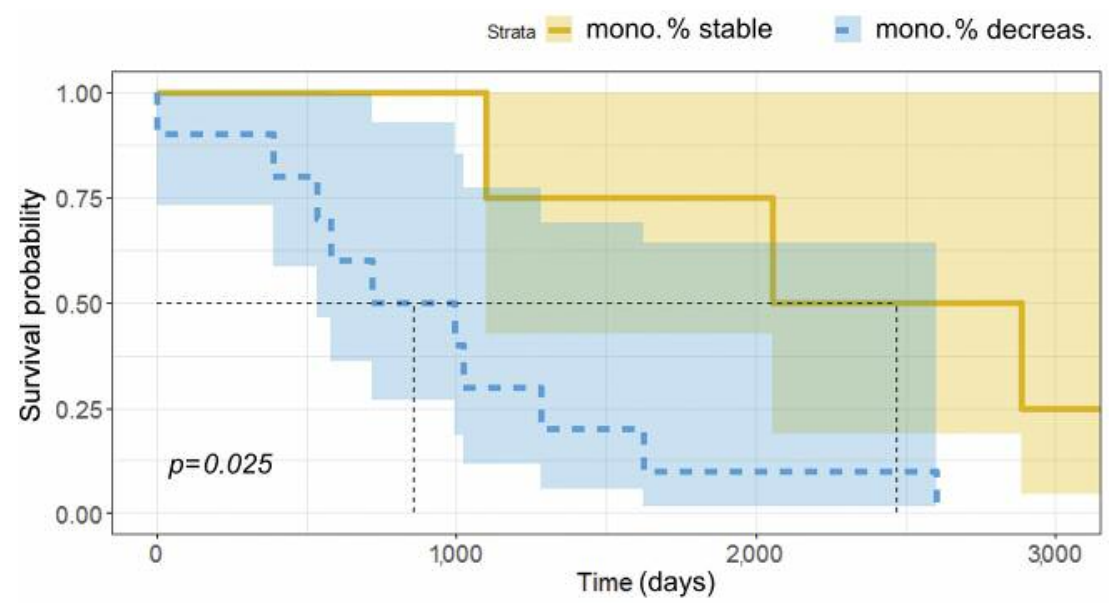

Figure 2. Overall survival investigation stratified by monocyte percentage changes (stable/increased versus decreased, Kaplan-Meyer curve with confidence intervals).

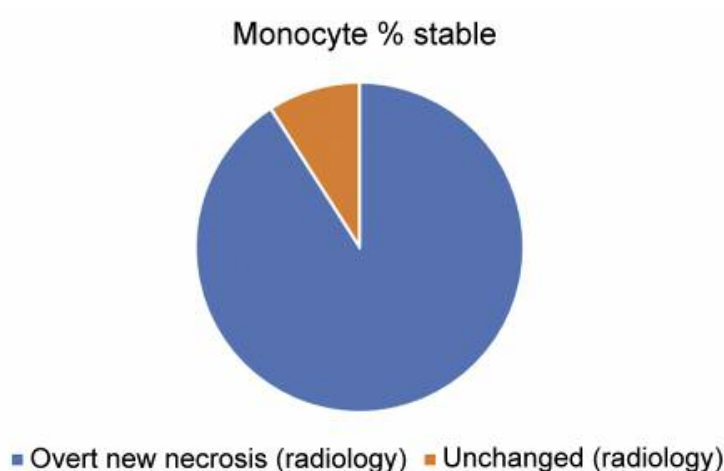

Figure 3. Radiological changes with new (central) necrosis occurring in patients treated with CCR5i stratified for monocyte percentage change.
Monocyte \% decreased

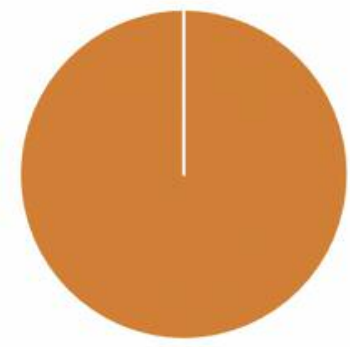

= Overt new necrosis (radiology) = Unchanged (radiology) ability to sustain the influx of monocytes and b) the dynamics of monocytes might be an early indicator of treatment outcome beyond radiologic findings.

It is clear that the available data from the trial are limited and there might be other aspects in the dynamics of cellular components or cytokines that have not been identified as relevant, e.g. due to the small number of patients and patient samples in this trial. This exploratory approach is only a first step in a translational attempt to form hypotheses for further validation in clinical trials. But the strength here is that analyses show as a proof-of-concept that peripheral blood analyses might be an early response marker linked to imaging results and overall course of the disease. Systematic analyses of peripheral blood samples are not routine, also due to the almost unlimited number of possible analytes, combinations and dynamics. However, these types of exploratory analyses can be first orientation points for deeper systematic analyses. Also, underlying pathophysiological assumptions can guide the selection for strategies to identify biomarkers or stratification parameters. The presented data make clear that simple systematic analyses like differential blood displays should become standard for immunotherapeutic trials. Given the high standards and standardization of these laboratory analyses, an additional set of robust parameters for immunotherapy can be obtained easily.

\section{Conclusion}

This work shows that monocyte dynamics are associated with the clinical efficacy of CCR5i in colorectal cancer. Also, our findings indicate that systematic inclusion of differential blood displays in addition to inflammatory markers in immunotherapy trials is an interesting and easily feasible option. More studies are needed to better illuminate the potential of monocyte dynamics in immunotherapies. 


\section{Conflicts of Interest}

The Authors declare no competing interests. NH and $\mathrm{AZ}$ are employees of University of Heidelberg, which is owner of a patent on the use of CCR5 inhibition for cancer treatment.

\section{Authors' Contributions}

Conceptualization: A.A., N.H.; methodology: A.A., N.H.; formal analysis: N.H.; investigation: A.A., N.H.; resources: N.H.; data curation: N.H.; writing-original draft preparation: A.A., N.H.; writingreview and editing: A.A., N.H.; visualization: A.A., N.H.; supervision: N.H.; project administration: N.H.; funding acquisition: N.H.

\section{Acknowledgements}

The Authors thank Rosa Eurich and Jana Wolf for expert technical assistance.

\section{References}

1 Di Caro G, Bergomas F, Grizzi F, Doni A, Bianchi P, Malesci A, Laghi L, Allavena P, Mantovani A and Marchesi F: Occurrence of tertiary lymphoid tissue is associated with t-cell infiltration and predicts better prognosis in early-stage colorectal cancers. Clin Cancer Res 20(8): 2147-2158, 2014. PMID: 24523438. DOI: $10.1158 / 1078-0432 . C C R-13-2590$

2 Di Caro G, Castino GF, Bergomas F, Cortese N, Chiriva-Internati M, Grizzi F, Mantovani A and Marchesi F: Tertiary lymphoid tissue in the tumor microenvironment: From its occurrence to immunotherapeutic implications. Int Rev Immunol 34(2): 123-133, 2015. PMID: 25901857. DOI: 10.3109/08830185.2015.1018416

3 Dieu-Nosjean MC, Giraldo NA, Kaplon H, Germain C, Fridman WH and Sautes-Fridman C: Tertiary lymphoid structures, drivers of the anti-tumor responses in human cancers. Immunol Rev 271(1): 260-275, 2016. PMID: 27088920. DOI: 10.1111/imr.12405

4 Kroemer G, Galluzzi L, Zitvogel L and Fridman WH: Colorectal cancer: The first neoplasia found to be under immunosurveillance and the last one to respond to immunotherapy? Oncoimmunology 4(7): e1058597, 2015. PMID: 26140250. DOI: 10.1080/216240 2X.2015.1058597

5 Le DT, Uram JN, Wang H, Bartlett BR, Kemberling H, Eyring AD, Skora AD, Luber BS, Azad NS, Laheru D, Biedrzycki B, Donehower RC, Zaheer A, Fisher GA, Crocenzi TS, Lee JJ, Duffy SM, Goldberg RM, de la Chapelle A, Koshiji M, Bhaijee F, Huebner T, Hruban RH, Wood LD, Cuka N, Pardoll DM, Papadopoulos N, Kinzler KW, Zhou S, Cornish TC, Taube JM, Anders RA, Eshleman JR, Vogelstein B and Diaz LA Jr.: Pd-1 blockade in tumors with mismatch-repair deficiency. N Engl J Med 372(26): 2509-2520, 2015. PMID: 26028255. DOI: 10.1056/NEJMoa1500596

6 Mlecnik B, Bindea G, Angell HK, Sasso MS, Obenauf AC, Fredriksen T, Lafontaine L, Bilocq AM, Kirilovsky A, Tosolini M, Waldner M, Berger A, Fridman WH, Rafii A, Valge-Archer V, Pages F, Speicher MR and Galon J: Functional network pipeline reveals genetic determinants associated with in situ lymphocyte proliferation and survival of cancer patients. Sci Transl Med 6(228): 228ra237, 2014. PMID: 24648340. DOI: 10.1126/scitranslmed.3007240
7 Bindea G, Mlecnik B, Tosolini M, Kirilovsky A, Waldner M, Obenauf AC, Angell H, Fredriksen T, Lafontaine L, Berger A, Bruneval P, Fridman WH, Becker C, Pages F, Speicher MR, Trajanoski Z and Galon J: Spatiotemporal dynamics of intratumoral immune cells reveal the immune landscape in human cancer. Immunity 39(4): 782-795, 2013. PMID: 24138885. DOI: $10.1016 /$ j.immuni.2013.10.003

8 Bindea G, Mlecnik B, Fridman WH, Pages F and Galon J: Natural immunity to cancer in humans. Curr Opin Immunol 22(2): 215222, 2010. PMID: 20207124. DOI: 10.1016/j.coi.2010.02.006

9 Pages F, Galon J, Dieu-Nosjean MC, Tartour E, Sautes-Fridman $\mathrm{C}$ and Fridman WH: Immune infiltration in human tumors: A prognostic factor that should not be ignored. Oncogene 29(8): 1093-1102, 2010. PMID: 19946335. DOI: 10.1038/onc.2009.416

10 Galon J, Costes A, Sanchez-Cabo F, Kirilovsky A, Mlecnik B, Lagorce-Pages C, Tosolini M, Camus M, Berger A, Wind P, Zinzindohoue F, Bruneval P, Cugnenc PH, Trajanoski Z, Fridman WH and Pages F: Type, density, and location of immune cells within human colorectal tumors predict clinical outcome. Science 313(5795): 1960-1964, 2006. PMID: 17008531. DOI: 10.1126/science.1129139

11 Halama N, Braun M, Kahlert C, Spille A, Quack C, Rahbari N, Koch M, Weitz J, Kloor M, Zoernig I, Schirmacher P, Brand K, Grabe N and Falk CS: Natural killer cells are scarce in colorectal carcinoma tissue despite high levels of chemokines and cytokines. Clin Cancer Res 17(4): 678-689, 2011. PMID: 21325295. DOI: 10.1158/1078-0432.CCR-10-2173

12 Van Cutsem E and Ducreux M: Colorectal and gastric cancer in 2015: The development of new agents and molecular classifications. Nat Rev Clin Oncol 13(2): 69-70, 2016. PMID: 26667973. DOI: 10.1038/nrclinonc.2015.217

13 Modest DP, Ricard I, Stintzing S, Fischer von Weikersthal L, Decker T, Kiani A, Vehling-Kaiser U, Al-Batran SE, Heintges T, Kahl C, Seipelt G, Kullmann F, Scheithauer W, Moehler M, Westphalen CB, Holch JW, von Einem JC, Held S, Heinemann $\mathrm{V}$ and for F-A-i: Evaluation of survival across several treatment lines in metastatic colorectal cancer: Analysis of the fire- 3 trial (aio krk0306). Eur J Cancer 84: 262-269, 2017. PMID: 28843184. DOI: 10.1016/j.ejca.2017.07.030

14 Kather JN and Halama N: Harnessing the innate immune system and local immunological microenvironment to treat colorectal cancer. Br J Cancer 120(9): 871-882, 2019. PMID: 6734657. DOI: $10.1038 / \mathrm{s} 41416-019-0441-6$

15 Jiao X, Nawab O, Patel T, Kossenkov AV, Halama N, Jaeger D and Pestell RG: Recent advances targeting ccr5 for cancer and its role in immuno-oncology. Cancer Res 79(19): 4801-4807, 2019. PMID: 31292161. DOI: 10.1158/0008-5472.CAN-19-1167

16 Halama N: Ccr5 inhibition in colorectal cancer patients. Transl Cancer Res 5(S2): S366-S367, 2016. DOI: 10.21037/tcr.2016.07.42

17 Halama N, Zoernig I, Berthel A, Kahlert C, Klupp F, SuarezCarmona M, Suetterlin T, Brand K, Krauss J, Lasitschka F, Lerchl T, Luckner-Minden C, Ulrich A, Koch M, Weitz J, Schneider M, Buechler MW, Zitvogel L, Herrmann T, Benner A, Kunz C, Luecke S, Springfeld C, Grabe N, Falk CS and Jaeger D: Tumoral immune cell exploitation in colorectal cancer metastases can be targeted effectively by anti-ccr5 therapy in cancer patients. Cancer Cell 29(4): 587-601, 2016. PMID. DOI: 10.1016/j.ccell.2016.03.005

18 Woodward Davis AS, Roozen HN, Dufort MJ, DeBerg HA, Delaney MA, Mair F, Erickson JR, Slichter CK, Berkson JD, 
Klock AM, Mack M, Lwo Y, Ko A, Brand RM, McGowan I, Linsley PS, Dixon DR and Prlic M: The human tissue-resident ccr5 $<$ sup $>+</$ sup $>t$ cell compartment maintains protective and functional properties during inflammation. Sci Transll Med 11(521): eaaw8718, 2019. PMID: 31801887. DOI: 10.1126/ scitranslmed.aaw8718

19 Dorr P, Westby M, Dobbs S, Griffin P, Irvine B, Macartney M, Mori J, Rickett G, Smith-Burchnell C, Napier C, Webster R, Armour D, Price D, Stammen B, Wood A and Perros M: Maraviroc (uk-427,857), a potent, orally bioavailable, and selective small-molecule inhibitor of chemokine receptor ccr5 with broad-spectrum anti-human immunodeficiency virus type 1 activity. Antimicrob Agents Chemother 49(11): 4721-4732, 2005 PMID: 16251317. DOI: 10.1128/AAC.49.11.4721-4732.2005

20 Halama N, Michel S, Kloor M, Zoernig I, Benner A, Spille A, Pommerencke T, von KnebelDM, Folprecht G, Luber B, Feyen N, Martens UM, Beckhove P, Gnjatic S, Schirmacher P, Herpel E, Weitz J, Grabe N and Jaeger D: Localization and density of immune cells in the invasive margin of human colorectal cancer liver metastases are prognostic for response to chemotherapy. Cancer Res 71(17): 5670-5677, 2011. PMID: 21846824. DOI: 10.1158/0008-5472.CAN-11-0268

21 Passardi A, Scarpi E, Tamberi S, Cavanna L, Tassinari D, Fontana A, Pini S, Bernardini I, Accettura C, Ulivi P, Frassineti GL and Amadori D: Impact of pre-treatment lactate dehydrogenase levels on prognosis and bevacizumab efficacy in patients with metastatic colorectal cancer. PLoS One 10(8): e0134732, 2015. PMID: 26244985. DOI: 10.1371/journal.pone.0134732

22 Caputo D, Coppola A, La Vaccara V, Angeletti S, Rizzo G, Ciccozzi M, Coco C and Coppola R: Neutrophil to lymphocyte ratio (nlr) predicts risk of nodal involvement in $\mathrm{t} 1$ colorectal cancer patients. Minerva Chir, 2018. PMID: 29652113. DOI: 10.23736/S0026-4733.18.07430-8

23 Palin RP, Devine AT, Hicks G and Burke D: Association of pretreatment neutrophil-lymphocyte ratio and outcome in emergency colorectal cancer care. Ann R Coll Surg Engl 100(4): 308-315, 2018. PMID: 29364006. DOI: 10.1308/rcsann.2017.0232

24 Guo D, Han A, Jing W, Chen D, Jin F, Li M, Kong L and Yu J: Preoperative to postoperative change in neutrophil-tolymphocyte ratio predict survival in colorectal cancer patients. Future Oncol 14(12): 1187-1196, 2018. PMID: 29302993. DOI: 10.2217/fon-2017-0659

25 Hirako IC, Ataide MA, Faustino L, Assis PA, Sorensen EW, Ueta H, Araujo NM, Menezes GB, Luster AD and Gazzinelli RT: Splenic differentiation and emergence of ccr5+cxc19+cxcl10+ monocyte-derived dendritic cells in the brain during cerebral malaria. Nat Commun 7: 13277, 2016. PMID: 27808089. DOI: $10.1038 /$ ncomms 13277
26 Madera L and Hancock RE: Anti-infective peptide idr-1002 augments monocyte chemotaxis towards ccr5 chemokines. Biochem Biophys Res Commun 464(3): 800-806, 2015. PMID: 26168734. DOI: 10.1016/j.bbrc.2015.07.038

27 Fox JM, Kasprowicz R, Hartley O and Signoret N: Ccr5 susceptibility to ligand-mediated down-modulation differs between human t lymphocytes and myeloid cells. J Leukoc Biol 98(1): 5971, 2015. PMID: 25957306. DOI: 10.1189/jlb.2A0414-193RR

28 Lee NJ, Choi DY, Song JK, Jung YY, Kim DH, Kim TM, Kim DJ, Kwon SM, Kim KB, Choi KE, Moon DC, Kim Y, Han SB and Hong JT: Deficiency of c-c chemokine receptor 5 suppresses tumor development via inactivation of nf-kappab and inhibition of monocyte chemoattractant protein-1 in urethane-induced lung tumor model. Carcinogenesis 33(12): 2520-2528, 2012. PMID: 22907530. DOI: $10.1093 /$ carcin/bgs265

29 Coussens LM, Zitvogel L and Palucka AK: Neutralizing tumorpromoting chronic inflammation: A magic bullet? Science 339(6117): 286-291, 2013. PMID: 23329041.

30 Ng-Cashin J, Kuhns JJ, Burkett SE, Powderly JD, Craven RR, van Deventer HW, Kirby SL and Serody JS: Host absence of ccr5 potentiates dendritic cell vaccination. J Immunol 170(8): 42014208, 2003. PMID: 12682253. DOI: 10.4049/jimmunol.170.8.4201

31 Abdi R, Smith RN, Makhlouf L, Najafian N, Luster AD, Auchincloss H, Jr. and Sayegh MH: The role of cc chemokine receptor 5 (ccr5) in islet allograft rejection. Diabetes 51(8): 24892495, 2002. PMID: 12145162. DOI: 10.2337/diabetes.51.8.2489

32 Bromley SK, Peterson DA, Gunn MD and Dustin ML: Cutting edge: Hierarchy of chemokine receptor and tcr signals regulating $\mathrm{t}$ cell migration and proliferation. J Immunol 165(1): 15-19, 2000. PMID: 10861029. DOI: 10.4049/jimmunol.165.1.15

33 Furuichi K, Wada T, Sakai N, Iwata Y, Yoshimoto K, Shimizu M, Kobayashi K, Takasawa K, Kida H, Takeda SI, Mukaida N, Matsushima K and Yokoyama H: Distinct expression of ccr1 and ccr5 in glomerular and interstitial lesions of human glomerular diseases. Am J Nephrol 20(4): 291-299, 2000. PMID: 10970982. DOI: 10.1159/000013603

34 Guo BY, Zhang SY, Mukaida N, Harada A, Kuno K, Wang JB, Sun SH and Matsushima K: Ccr5 gene expression in fulminant hepatitis and dth in mice. World J Gastroenterol 4(1): 14-18, 1998. PMID: 11819219. DOI: 10.3748/wjg.v4.i1.14

Received September 29, 2020

Revised October 12, 2020

Accepted October 16, 2020 